174

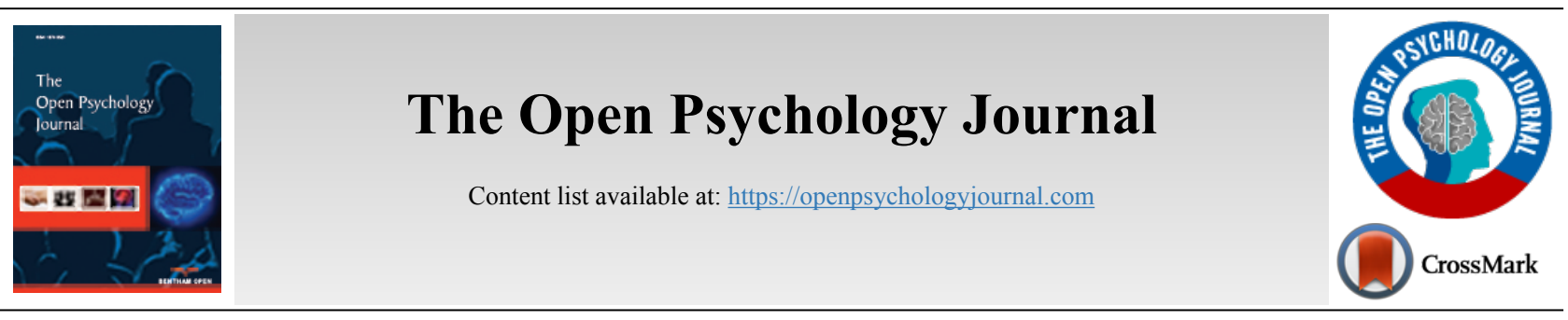

RESEARCH ARTICLE

\title{
The Motivation of Russian and Kazakhstani Faculty Members in the Cross- Cultural Context
}

\author{
Aizhan Turgumbayeva $^{1, *}$, Olga Aimaganbetova ${ }^{2}$, Roza Kassymova ${ }^{3}$, Elmira Yeralina ${ }^{4}$ and Zhanat Bakirova ${ }^{5}$ \\ ${ }^{1}$ Department of Psychology, Turan University, Almaty, Republic of Kazakhstan \\ ${ }^{2}$ Department of Psychology, Al-Farabi Kazakh National University, Almaty, Republic of Kazakhstan \\ ${ }^{3}$ Department of Pedagogy and Educational Management, Al-Farabi Kazakh National University, Almaty, Republic of Kazakhstan \\ ${ }^{4}$ Department of Management, Turan University, Almaty, Republic of Kazakhstan \\ ${ }^{5}$ Academy of Design and Technology "Symbat", Almaty, Republic of Kazakhstan
}

\begin{abstract}
:
Background \& Objective:

The motivation of university faculty members in a cross-cultural context is one of the main issues in the context of internationalization of higher education. This research aims to explore if there are significant differences in motivational drivers between Kazakhstani and Russian university faculty members based on their cultural background.

Methods:

The research involves 158 university faculty members from Kazakhstan and Russia. The research applies cross-survey methodology.

Results:

The findings on the main motivational themes show that Kazakhstani university faculty members have a higher orientation to security and stability and integration of lifestyle. Russian university faculty members have higher levels of autonomy, challenge and entrepreneurship.

Conclusion:

The conducted research presented the main motivational drivers of Kazakhstani and Russian faculty. It is evident that Kazakhstani and Russian university faculty members have significant differences in motivational profiles, despite the shared Soviet past. Research showed that Russian faculty is motivated by creativity and challenges, whereas their Kazakhstani counterparts seem to be more focused on the security and work-life balance. Nevertheless, the occupational peculiarities show similarities in the attitudes to money and power.
\end{abstract}

Keywords: Faculty motivation, Cross-cultural research, Higher education, Socio-psychological attitudes, Internationalization, Methodology.

\begin{tabular}{|l|l|l|l|}
\hline Article History & Received: May 02, 2019 & Revised: September 16, 2019 & Accepted: September 23, 2019
\end{tabular}

\section{INTRODUCTION}

The faculty motivation is one of the burning issues in the development of the higher education system in Kazakhstan and Russia [1]. After the collapse of the Soviet Union in 1991 and within the emerging crisis, many faculty members in newly formed countries were demotivated and quitted university jobs due to uncertainty and low pay rate [2]. In the context of new economics and political realities, both Kazakhstan and Russia adopted best international practices, integrating into the global

\footnotetext{
* Address correspondence to this author at the Navoi 37 str, office 98, 050034, Almaty, Republic of Kazakhstan; Tel: +77010986628;

E-mail: aizhan.turgumbayeva@nu.edu.kz
}

educational space, which put them in front of the need to implement a new higher education development strategy including participation in the Bologna process and overall renewal of higher education $[3,4]$.

The current research study aims to explore the motivational traits of faculty members in Kazakhstan and Russia. Due to the geographical closeness and mutual socio-economic past, these two countries have developed close relationships in many areas including higher education. Thus, the study of possible similarities and differences in motivation of some leading individuals in the educational sphere is crucial to design an adequate and effective educational curriculum. 
The main hypothesis of the research is the assumption that there are existing differences in motivational drivers between Kazakhstani and Russian university faculty members based on their cultural traits. In this sense, the study of university faculty members' motivation in a cross-cultural context is an important aspect and necessary in the study of socio-psychological phenomena. The study of cross-cultural differences opens new horizons and promising direction in the field of university faculty members' motivation for post-Soviet Union perimeter, as well as new contexts for the new problems unknown from past experiences $[5,6]$.

\section{LITERATURE REVIEW}

The issue of faculty members motivation has been studied from various point of views by different scholars. Schneider \& Zalesny (1981) studied faculty motivation through the prism of needs theory to prove that the right attitude towards work is possible after the fulfillment of other basic needs [7]. This idea is also reflected in the work of Holliman \& Daniels (2018) who linked motivation with economic situation [8]. As it was stated by Feldman \& Paulsen (1999), the constant transformation of higher education system can also affect the motivation of faculty members [9]. According to Rashidi, Zaki \& Al Jalbani (2012), university faculty members face more pressure due to the transformation of higher education system; the professional activity of university faculty proceeds against the background of obvious problems, the most acute of them are low public prestige of the teaching and scientific professions and the outflow of highly qualified personnel [10].

As stated by Heyneman (2010), university faculty members often do not consider their activity in it as the major ones; consequently, have low motivation to work in the scientific and teaching field [11]. This statement to a larger extent is supported by Chauhan, Goel \& Arora (2018) who additionally emphasize the fact that effectiveness of faculty activities is a combination of number of factors, including core motivation, personality and training [12].

The issue of faculty motivation in Kazakhstan and Russia is usually researched from the perspective of the post-Soviet era. Nesipbayeva \& Dalayeva (2013) argue that having the similar Soviet Union background not only in educational systems, but also in general ideology, nowadays these countries have a different set of cultural values and many personal characteristics including professional motivation [13]. The similar views are also presented by Ardichvili \& Gasparishvili (2001) who revealed visible differences in value orientation and leadership styles that can be seen as the main drivers of motivation of post-Soviet countries [14]. In addition, Bendas (2013) emphasized the existing differences in Kazakhstani and Russian population in terms of ethnocultural nature and gender [15].

\section{METHODOLOGY}

\subsection{Sampling}

The research participants are university faculty members from Kazakhstan and Russia. Research participants were selected through random sampling technique based on the availability and willingness to participate among the target population [16].

The total number of participants is 158 people. Kazakhstani sample consists of 80 university faculty members from two cities - Almaty and Nur-Sultan. Russian sample also consists of 78 faculty members from universities in Moscow.

As can be seen in Table 1, the gender split highlights predominantly women population among Kazakhstani participants ( $\mathrm{F}=51, \mathrm{M}=29)$, however, a more balanced split can be seen among the Russian population $(\mathrm{F}=36, \mathrm{M}=42)$. The majority of participants in both the samples are between 31 and 50 years old (56.2\% in Kazakhstan and 50\% in Russia). Both Kazakhstan and Russia have a significant number of participants with more than 31 years of work experience $(20 \%$ in Kazakhstan and $34.6 \%$ in Russia), whereas the average tenure lies within the group of 11-30 years.

Table 1. Demographic information of the samples.

\begin{tabular}{|c|c|c|}
\hline \multicolumn{2}{|c|}{ Kazakhstani Sample (n=80) } & Russian Sample (n=78) \\
\hline Items & $\mathbf{N ~ ( \% )}$ & $\mathbf{N}(\mathbf{\%})$ \\
\hline Gender & & \\
\hline Male & $29(36.2)$ & $42(53.8)$ \\
\hline Female & $51(63.8)$ & $36(46.2)$ \\
\hline Age Category & & \\
\hline$<30$ years & $11(13.8)$ & $8(10.2)$ \\
$31-50$ years & $45(56.2)$ & $39(50)$ \\
$>51$ years & $24(30)$ & $31(39.8)$ \\
\hline Career Duration & & \\
\hline$<10$ years & $15(18.8)$ & $9(11.5)$ \\
$11-30$ years & $49(61.2)$ & $42(53.9)$ \\
$>31$ years & $16(20)$ & $27(34.6)$ \\
\hline Type of University & & \\
\hline National University & $38(47.5)$ & $41(52.5)$ \\
State University & $18(22.5)$ & $21(27)$ \\
Private University & $24(30)$ & $16(20.5)$ \\
\hline
\end{tabular}

\subsection{Measures}

The research applies E. Schein's "Career anchors" questionnaire, which identifies the main themes that drive an individual's career [17]. Estimations of statements are made on a 10-point scale. Total points on all scales reflect the structure of professional motivation - the significance of career orientations. The following main groups are presented in the questionnaire: technical and functional competency (TF), Managerial Competency (MC), Autonomy and Independence (AI), Safety and Stability (SS), Service and Dedication (SD), Pure Challenge (PC), Lifestyle (L), and Entrepreneurial Creativity (EC).

In order to identify the socio-psychological attitudes, we applied O. Potemkina's method of diagnostics of the sociopsychological settings of the individual in the motivationalneed sphere. The method of identifying socio-psychological attitudes measures the following continuums "altruismegoism", "process-result", and "freedom-power". The concept of "socio-psychological settings" means a state of psychological readiness, which is formed on the basis of personal experience and has a direct impact on possible 
reactions of a person. At the same time, "installation" is considered not as a relation to any object, phenomenon, or a person, but as readiness for a certain behavior in a specific situation. In turn, the essence of the motivational-need sphere of the personality means a kind of foundation on which the life goals of the personality are formed, which determine the life path [18].

To assess the level of perceived professional success of university faculty members, we added in the questionnaire major pre-selected success indicators: Professional Expertise (PE); Communicative Competency (CC); Pedagogical Competency (PEC); and Innovation (IN). The Likert-scale consists of 10 points, when 10 is the highest value and 1 is the lowest one.

\subsection{Statistical Analysis}

The data was analyzed with the STATISTICA statistical package. Mann-Whitney U-test was applied to identify statistically significant differences between psychological indicators and Spearman rank correlation in order to measure the strengths between two variables.

The Mann-Whitney test provides a nonparametric alternative to the t-test for independent samples. Its advantage is that we abandon the assumption that the distribution is normal, and the variances are the same.

\subsection{Data Collection}

Data was collected during the 2017-2018 academic year from universities in Kazakhstan and Russia. The participants were reached through the administration of the institutions that provided their work e-mails. Research participants received invitations to participate via e-mails with the link to the electronic questionnaire. The participants were informed about the description of the research purpose, their right to withdraw at any moment and absolutely anonymity of their answers.

\section{RESULTS}

Table 2 shows the findings regarding Kazakhstani and Russian university faculty members' main motivational themes within eight main categories: technical and functional competence (TF), Managerial Competence (MC), Autonomy and Independence (AI), Security and Stability (SS), Service and Dedication (SD), Pure Challenge (PC), Lifestyle (L) and Entrepreneurial Creativity (EC).

The findings on the main motivational themes show that Kazakhstani university faculty members have higher orientation to security and stability $(U=282, p<0.05)$, service $(\mathrm{U}=168.5, \mathrm{p}<0.05)$ and integration of lifestyle $(\mathrm{U}=140.5, \mathrm{p}$ $<0.05)$. The high degree of stability means that specialists feel the need for a permanent, safe place of work. Probably, such a need is formed due to the fact that the modern system of higher education in Kazakhstan has undergone significant changes in recent years, and the university faculty members were not protected from sudden changes and new demands on themselves. For Kazakhstani university faculty members, orientation toward the integration of lifestyles, service and stability is of the greatest importance. The lowest average value for university faculty members of higher educational institutions of Kazakhstan is entrepreneurship.

Russian university faculty members have higher levels of autonomy $(\mathrm{U}=125.5, \mathrm{p}<0.05)$, challenge $(\mathrm{U}=121.5, \mathrm{p}<0.05)$ and entrepreneurship $(U=107.5, p<0.05)$, than their colleagues from Kazakhstan. All these orientations are associated with individualistic Western values, which every year become more and more expressed in Russian society, especially in larger cities. Among Russian university faculty members, career orientations for autonomy, challenge and entrepreneurship also have a high average value that can be associated with the cultural features of modern Russia. The lowest indicator in the Russian sample is the integration of lifestyle.

It is evident that career orientation toward technical and functional competence is most pronounced in both samples. This means that it is important for university faculty members in both the countries to be professionals in their field, to constantly improve their professional skills and competencies, and to increase the level of knowledge. This is a positive trend, we associate it, among other things, with the fact that both the countries are going through the modernization phase of education, one aspect of which is raising the qualification requirements of the teaching staff. Thus, the new educational system is aimed at disregarding those employees who do not keep pace with the high quality of their work.

Kazakhstani and Russian university faculty members have significant differences in most career orientations. This means that in many aspects, they have different professional motivation and focus on different areas of professional activity. At the same time, there is no difference in such points as technical and functional competence and managerial competence. University faculty members in both Kazakhstan and Russia have strong pronounced motivation to become masters in their field. Thus, we can assume that the modern education system in both the countries attracts ambitious, highly motivated personnel.

Table 3 shows the findings of the socio-psychological attitudes of the individuals in the motivational-need sphere of higher education faculty members in Kazakhstan and Russia. In Kazakhstani university faculty members, there is significantly higher intensity of the following attitudes: process orientation $(U=90.5, p<0.05)$, altruism $(U=211.5, p<0.05)$ and labor $(U=212, p<0.05)$. Orientation to the process says that they are driven by more interest in the work than the achievement of the result; the procedural component of their work is important to them. Analyzing the significant statistical differences we see that Russian university faculty members have a greater focus on results $(U=101.5, p<0.05)$, egoism ( $U$ $=276, p<0.05)$ and freedom $(U=173, p<0.05)$ than their counterparts from Kazakhstan. Result orientation characterizes high motivation in achieving goals in spite of obstacles. This overlaps with career-oriented challenges and professional competence.

Interestingly, both the groups were observed to be less interested in power. Additionally, Kazakhstani university faculty members have the least significant attitude towards result and freedom, whereas their Russian colleagues are less altruistic and process-oriented. 
Table 2. Career motivational themes of Kazakhstani and Russian faculty members.

\begin{tabular}{|c|c|c|c|c|c|c|c|c|}
\hline- & Mean & SD & $\alpha$-Cronbach & Mean & SD & $\alpha$-Cronbach & \multirow{2}{*}{ Mann-Whitney U-test } & \multirow{2}{*}{$P$ value } \\
\hline & \multicolumn{3}{|c|}{ Kazakhstani Sample } & \multicolumn{3}{|c|}{ Russian Sample } & & \\
\hline $\mathrm{TF}$ & 8,13 & 1,27 & 0,7 & 8,07 & 1,17 & 0,71 & 436,5 & 0,838 \\
\hline $\mathrm{MC}$ & 5,83 & 0,91 & 0,82 & 5,90 & 1,09 & 0,86 & 429,5 & 0,747 \\
\hline AI & 5,30 & 1,2 & 0,71 & 7,50 & 1,57 & 0,64 & 125,5 & $0,001^{*}$ \\
\hline SS & 7,03 & 1,35 & 0,7 & 6,13 & 1 & 0,75 & 282 & $0,01 *$ \\
\hline SD & 7,63 & 1,24 & 0,76 & 6,07 & 1,12 & 0,81 & 168,5 & $0,001^{*}$ \\
\hline PC & 5,53 & 1 & $\mathbf{0 , 7 3}$ & 7,37 & 1,27 & 0,77 & 121,5 & $0,001^{*}$ \\
\hline $\mathbf{L}$ & 7,73 & 1,52 & 0,8 & 5,67 & 1,21 & 0,72 & 140,5 & $0,001^{*}$ \\
\hline EC & 5,17 & 0,69 & 0,74 & 7,13 & 1,45 & 0,68 & 107,5 & $0,001^{*}$ \\
\hline
\end{tabular}

Table 3. Socio-psychological attitudes of the individual in the motivational-need sphere.

\begin{tabular}{|c|c|c|c|c|c|c|c|c|}
\hline \multirow{2}{*}{-} & $\mathbf{M}$ & SD & $\alpha$-Cronbach & $\mathbf{M}$ & SD & a-Cronbach & \multirow{2}{*}{ Mann-Whitney U-test } & \multirow{2}{*}{$P$ value } \\
\hline & \multicolumn{3}{|c|}{ Kazakhstani Sample } & \multicolumn{3}{|c|}{ Russian Sample } & & \\
\hline Process & 7,90 & 1,38 & 0,74 & 5,67 & 0,99 & 0,69 & 90,5 & $0,001^{*}$ \\
\hline Result & 5,57 & 1,1 & 0,78 & 7,70 & 1,29 & 0,75 & 101,5 & $0,001^{*}$ \\
\hline Altruism & 7,10 & 1,21 & 0,81 & 5,8 & 1,32 & 0,76 & 211,5 & $0,001 *$ \\
\hline Egoism & 5,8 & 1,03 & 0,84 & 6,53 & 1 & 0,73 & 276 & $0,007^{*}$ \\
\hline Labor & 7,73 & 1,25 & 0,76 & 6,57 & 1,1 & 0,82 & 212 & $0,001^{*}$ \\
\hline Freedom & 5,2 & 1,09 & 0,72 & 7,03 & 1,18 & 0,74 & 123,0 & $0,001^{*}$ \\
\hline Power & 4,73 & 1,01 & 0,71 & 4,97 & 1,18 & 0,71 & 417 & 0,61 \\
\hline Remuneration & 5,87 & 0,89 & 0,7 & 6,53 & 1,33 & 0,75 & 319 & 0,052 \\
\hline
\end{tabular}

As can be seen from Table $\mathbf{4}$, the professional success indicators do not differ significantly between the groups and have rather a high score. Also, no differences were identified in the level of professional and pedagogical competence. The university faculty members in Kazakhstan demonstrate a significantly high level of communicative competence $(\mathrm{U}=$ $287, \mathrm{p}<0.05$ ). We have repeatedly stressed on the importance of communication and interpersonal interaction for the Kazakh culture. In the Russian sample, the level of innovativeness is significantly higher than in Kazakhstan $(U=314, p<0.05)$. We have already said that to a greater extent, the Russian educational structure at the moment stimulates university faculty members' independence, their initiatives and creativity; all these leading toinnovativeness. In addition, innovative approach and innovation give university faculty members a favorable competitive advantage among their colleagues, which allows them to receive additional encouragement.

\subsection{Correlational Analysis}

Table 5 presents the correlational analysis of the relationship between career motivational drivers and success indicators of Kazakhstani and Russian university faculty members.

Kazakhstani sample shows the significant positive relationships among professional expertise and technical and functional competency $\left(0.81^{*}\right)$, safety and stability $\left(0.69^{*}\right)$, service and dedication $\left(0.65^{*}\right)$ and lifestyle $(0.74 *)$. On the other hand, the correlational analysis shows that for Russian university faculty members, the success of their professional activities has significant positive relationships with the following motivational drivers: technical and functional competence $(0.772 *)$, autonomy and independence $\left(0.71^{*}\right)$, pure challenge $\left(0.65^{*}\right)$, entrepreneurial creativity $\left(0.73^{*}\right)$, and a significant negative relationship with safety and stability $(-0.18)$.

The correlations of the socio-psychological attitudes of the individuals in the motivational-need sphere and the professional success of university faculty members in Kazakhstan and Russia show significant differences in motivational factors.

As can be seen from Table 6, for the Russian sample, significant interrelations are evident between results and professional expertise $\left(0.68^{*}\right)$, pedagogical competency $\left(0.45^{*}\right)$ and innovativeness $\left(0.72^{*}\right)$. Additionally, there are significant positive relations among freedom and professional expertise $\left(0.67^{*}\right)$ and remuneration and innovativeness $\left(0.55^{*}\right)$. In the group of university faculty members in Kazakhstan, the following positive relationships have been identified: between professional expertise and process orientation $\left(0.74^{*}\right)$ and labor $\left(0.72^{*}\right)$, communicative competency and altruism $\left(0.76^{*}\right)$.

\section{DISCUSSION}

Research shows that despite the similarities in educational, economic and social dimensions, Russian and Kazakhstani university faculty members have significant differences in their motivational traits. The main motivational drivers for Kazakhstani participants are security, stability, service and integration of lifestyle. The strong orientation to service can be related to the willingness to benefit society and people and embody their values and ideals in it [19]. It is also very impor- 
Table 4. The indicators of success for university faculty members in Kazakhstan and Russia.

\begin{tabular}{|c|c|c|c|c|c|c|}
\hline$\cdot$ & $\begin{array}{c}\text { Mean (Russian } \\
\text { Sample) }\end{array}$ & SD (Russian Sample) & Mean (Kazakhstani Sample) & SD (Kazakhstani Sample) & Mann-Whitney U-Test & $\boldsymbol{P}$-value \\
\hline PE & 8,0 & 1,33 & 7,57 & 1,38 & 369 & 0,220 \\
\hline CC & $\mathbf{6 , 8 3}$ & $\mathbf{1 , 0 5}$ & $\mathbf{7 , 7}$ & $\mathbf{1 , 4 1}$ & $\mathbf{2 8 7}$ & $0,013 *$ \\
\hline PEC & 7,4 & 0,93 & 8,07 & 1,46 & 335 & 0,078 \\
\hline IN & $\mathbf{7 , 4}$ & $\mathbf{1 , 4 9}$ & $\mathbf{6 , 5 7}$ & $\mathbf{1 , 5}$ & $\mathbf{3 1 4}$ & $0,041^{*}$ \\
\hline
\end{tabular}

Table 5. Correlational analysis of career orientations and success indicators.

\begin{tabular}{|c|c|c|c|c|c|c|c|c|}
\hline & \multicolumn{4}{|c|}{ Kazakhstani Sample } & \multicolumn{4}{|c|}{ Russian Sample } \\
\hline & $\mathbf{P E}$ & $\mathrm{CC}$ & PEC & IN & $\mathbf{P E}$ & $\mathrm{CC}$ & PEC & IN \\
\hline $\mathrm{TF}$ & $0,81 *$ & $0,8 *$ & $0,8^{*}$ & $0,58 *$ & $0,772 *$ & $0,5^{*}$ & $0,573 *$ & $0,771^{*}$ \\
\hline $\mathrm{MC}$ & 0,14 & 0,13 & 0,12 & 0,13 & $-0,15$ & $-0,16$ & 0,06 & 0,23 \\
\hline $\mathbf{A I}$ & $-0,06$ & 0,06 & $-0,1$ & 0,04 & $0,71 *$ & 0,36 & $0,43 *$ & $0,47^{*}$ \\
\hline SS & $0,69 *$ & $0,69 *$ & $0,71 *$ & $0,49 *$ & $-0,18$ & $-0,57 *$ & $-0,45 *$ & $-0,28$ \\
\hline SD & $0,73 *$ & $0,65 *$ & $0,65 *$ & 0,35 & 0,16 & $0,36^{*}$ & 0,19 & 0,28 \\
\hline PC & $-0,17$ & $-0,21$ & $-0,06$ & $-0,06$ & $0,65 *$ & $0,52 *$ & $0,61 *$ & $0,66^{*}$ \\
\hline $\mathbf{L}$ & $0,77 *$ & $0,74 *$ & $0,66^{*}$ & $0,47 *$ & 0,05 & $-0,7$ & $-0,15$ & $-0,12$ \\
\hline EC & $-0,09$ & $-0,07$ & 0,01 & 0,09 & $0,73 *$ & $0,51^{*}$ & $0,37 *$ & $0,58^{*}$ \\
\hline
\end{tabular}

Table 6. Correlational analysis of socio-psychological attitudes of the individual in the motivational-need sphere and success indicators.

\begin{tabular}{|c|c|c|c|c|c|c|c|c|}
\hline \multirow[b]{2}{*}{ Scales } & \multicolumn{4}{|c|}{ Kazakhstani Sample } & \multicolumn{4}{|c|}{ Russian Sample } \\
\hline & $\overline{P E}$ & $\mathrm{CC}$ & PEC & IN & PE & $\mathrm{CC}$ & PEC & IN \\
\hline Process & $0,74^{*}$ & $0,7^{*}$ & $0,67 *$ & $0,6^{*}$ & $-0,07$ & 0,001 & $-0,21$ & $-0,07$ \\
\hline Result & 0,05 & 0,22 & 0,18 & 0,19 & $0,68^{*}$ & $0,38^{*}$ & $0,45^{*}$ & $0,72 *$ \\
\hline Altruism & $0,6^{*}$ & $0,76^{*}$ & $0,56^{*}$ & $0,5^{*}$ & $-0,1$ & $-0,21$ & $-0,31$ & $-0,28$ \\
\hline Egoism & 0,16 & $-0,04$ & 0,22 & 0,08 & $-0,3$ & $-0,27$ & $-0,09$ & $-0,5$ \\
\hline Labor & $0,72^{*}$ & $0,62 *$ & $0,69 *$ & $0,43 *$ & 0,2 & 0,014 & 0,22 & 0,16 \\
\hline Freedom & $-0,04$ & $-0,006$ & $-0,03$ & 0,01 & $0,67^{*}$ & 0,36 & $0,37^{*}$ & $0,38^{*}$ \\
\hline Power & $-0,17$ & $-0,12$ & $-0,21$ & 0,013 & $-0,25$ & $-0,35$ & $-0,09$ & 0,11 \\
\hline Remuneration & $-0,14$ & $-0,24$ & $-0,23$ & 0,02 & $0,39 *$ & 0,18 & $0,41 *$ & $0,55^{*}$ \\
\hline
\end{tabular}

tant to perform at high level for Kazakhstani people, which is related to the universalist and collectivist values [20]. Perhaps that is why Kazakhstani university faculty members are consciously involved in this profession in order to serve the society of their country, to bring direct benefit by teaching young people. Such a component of their work as an orientation towards the welfare of other people can be highly valued in the society and serve as an important motivational trait [21]. The integration of lifestyle is another important factor that is evident for Kazakhstani sample. Researchers studying cultural values of Kazakhstan agree that family plays a key role in the life of the people of Kazakhstan. Family relationships remain extremely important, this distinguishes Kazakhstan from modern Russia, where the institution of the family is undergoing significant changes, and family ties are becoming increasingly weak. The findings correlate with the existent research that claims that for Kazakhs, it is extremely important to balance family and work, while, of course, personal life and family should not suffer any hardship because of work [22].
The research findings show that Russian university faculty members are driven by autonomy, challenge and entrepreneurial creativity. All these orientations are associated with individualistic Western values, which every year are more dominantly expressed in Russian society, especially in larger cities [23]. A high level of autonomy means that university faculty members value freedom and independence in their own work. Indeed, in many leading Moscow universities, the requirements for readable courses are more flexible. Nowadays, faculty members get more freedom for creativity both in the design of the curriculum and in the teaching process. In addition to autonomy, Russian teachers have a high level of career-oriented challenges. This means that they are focused on solving complex unique problems; they are not afraid of difficulties in their career paths [24]. The entrepreneurial environment also is one of the motivational traits of Russian university faculty members. As it was outlined in various research works, innovation and entrepreneurial creativity are important aspects of teaching and research in higher educational institutions [25]. 
University faculty members of both the countries quite strongly differ in socio-psychological attitudes of the personality in the motivational-need sphere. Kazakhstani university faculty members have significantly greater severity of the following indicators: process orientation, altruism and labor. Orientation to the process says that they are driven by more interest in the work than the achievement of the result, the procedural component and content of the work can be seen as the strong motivational driver. The prevailing focus on altruism has already been partially discussed earlier in the context of importance of the common good for Kazakh culture, moreover, the emphasis on the work and its quality remains to be the leading goal [26].

Russian university faculty members have a strong result orientation that characterizes high motivation in achieving goals in spite of obstacles. This may also be due to the fact that many Russian universities themselves create such a situation for their teaching staff, demanding from it a demonstration of high performance. Russian educators also have a higher orientation toward egoism that means that they value and care about their own interests. As mentioned above, and as shown by many studies in recent years, Russian culture has demonstrated a fairly high level of individualism, which, in turn, at the level of an individual, gives rise to "healthy egoism". Also, higher education institutions in Russia have a higher motivational need for freedom; this fully corresponds to the high career orientation for autonomy identified earlier, and also to individualistic values for which independence and freedom of self-expression are important [27].

No significant differences were found between the two samples for targeting money and power. Both of these motivational indicators have an average severity both in the group of Russian and in the group of Kazakhstani university faculty members. It is worth noting that this is most likely due to the fact that material motivation is not the main driver for people to pursue a career in higher education institutions, as despite the constant reforms, pay rate is still low in both Russia and Kazakhstan [28].

Research shows that both Kazakhstani and Russian university faculty members share the same indicators of professional success, such as professional competency, communicative competency, pedagogical competency and innovation in teaching and research. This once again confirms the fact that the new educational system introduced in Russia and Kazakhstan with special respect belongs to the professionalism of the teaching staff. In order to implement the educational principles prescribed in the Bologna Education Agreement and implement the competency approach in higher education, it is necessary that those people who teach students have all the necessary skills and competencies to constantly develop in a professional way.

The correlation analysis allowed to establish a number of patterns. Firstly, there appear to be culturally universal predictors of professional success, which proved to be the same in both the countries: this is an orientation towards professional competence and labor. Thus, we can say that the focus on the quality of work performed, on increasing the level of their professionalism and confident internal motivation of the activities performed guarantee the success of the faculty members regardless of cultural conditions and external factors. At the same time, differences were revealed in the manifestation of interrelations between motivational features and the success of the professional activity. The main motivational factors of Russian university faculty members are autonomy, challenge, and entrepreneurship. They can also be described as result-oriented, focusing on freedom and remuneration. On the other hand, their Kazakhstan counterparts are motivated by stability, service and lifestyle and can be seen as more process-oriented, altruistic and work-focused. In this regard, we can assume that the cultural and educational environment dictates its specific success criteria, encouraging certain qualities and motivational attitudes.

\section{CONCLUSION}

The research of university faculty members' motivation in a cross-cultural context let us see the main differences and similarities in Kazakhstan and Russia. It is evident that Kazakhstani and Russian university faculty members have significant differences in motivational profiles. More precisely, Kazakhstani faculty members are driven by stability, service and the lifestyle opportunities and are more process-oriented in their professional activities, whereas their Russian colleagues are motivated by autonomy in work, challenges and opportunities for entrepreneurship, as well as the feasible results. The findings confirm the research hypothesis that there are differences in the motivation of university faculty members in higher educational institutions of Kazakhstan and Russia, due to cultural peculiarities and the specifics of organizing education in universities. The research findings can have implications for the administration of further joint-educational programs and projects among Kazakhstani and Russian higher education institutions and build the foundation for further research on motivational drivers on post-Soviet perimeter.

\section{THEORETICAL AND PRACTICAL IMPLICATIONS}

The findings of the current research can set the foundation of further research on faculty members motivation in postSoviet countries. Moreover, the lack of such research on Kazakhstani and Russian faculty members can lead to the inclusion of these samples in further international crosscultural studies. In addition, in the context of curriculum design, a better understanding of motivational drivers can lead to a more advanced level of cooperation among Kazakhstani and Russian faculty members.

\section{LIMITATIONS}

The limitation of the study is the disbalance of research samples when one group (Kazakhstani faculty members) was dominant in number. Thus, in the future research, it is important to keep the same number of participants for all research sample groups. Another limitation is the absence of qualitative part that might show us some unraveled differences and similarities in the context of motivational drivers. In this context, qualitative research is expected to be the focus of the next research study. 


\section{ETHICS APPROVAL AND CONSENT TO PARTI- CIPATE}

Not applicable.

\section{HUMAN AND ANIMAL RIGHTS}

No animals/humans were used for studies that are the basis of this research.

\section{CONSENT FOR PUBLICATION}

Not applicable.

\section{AVAILABILITY OF DATA AND MATERIALS}

Not applicable.

\section{FUNDING}

None.

\section{CONFLICT OF INTEREST}

The authors declare no conflict of interest, financial or otherwise.

\section{ACKNOWLEDGEMENTS}

The research team would like to express sincere gratitude to higher education institutions that participated in the study.

\section{REFERENCES}

[1] Vlassov AV, Filippov YM. Russia and Kazakhstan: Reform of higher education. Lomonosov MSU Herald 2006; 12(01): 5-8.

[2] Azimbayeva G. Comparing post-Soviet changes in higher education governance in Kazakhstan, Russia, and Uzbekistan. Cogent Education 2017; 4(1)1399968

[http://dx.doi.org/10.1080/2331186X.2017.1399968]

[3] Johnson MS. Historical legacies of Soviet higher education and the transformation of higher education systems in post-Soviet Russia and Eurasia. 2008

[http://dx.doi.org/10.1016/S1479-3679(08)00006-6]

[4] Yergebekov M, Temirbekova Z. The Bologna process and problems in higher education system of Kazakhstan. Procedia Soc Behav Sci 2012; 9(47): 1473-8.

[http://dx.doi.org/10.1016/j.sbspro.2012.06.845]

[5] Hofstede G. Dimensionalizing cultures: The Hofstede model in context. Online Read Psychol Cult 2011; 2(1): 8-9. [http://dx.doi.org/10.9707/2307-0919.1014]

[6] Laurent A. The cross cultural puzzle of international human resource management. Hum Resour Manage 1986; 25(1): 91-102. [http://dx.doi.org/10.1002/hrm.3930250107]

[7] Schneider B, Zalesny MD. Human Needs and Faculty Motivation 1981.

[8] Holliman A, Daniels J. Faculty motivation in challenging times: Do leadership and economic conditions matter? Plann High Educ 2018; 47(1): 49

[9] Feldman KA, Paulsen MB. Faculty motivation: The role of a supportive teaching culture. New directions for teaching and learning.
1991; 1999(78): 69-78

10] Rashidi Z, Zaki S, Ali Jalbani A. Exploring the factors influencing faculty motivation and satisfaction in tertiary education. IBA Business Review 2016; 11(1): 15-20.

11] Heyneman SP. A comment on the changes in higher education in the former Soviet Union. Eur Educ 2010; 42(1): 76-87.

[http://dx.doi.org/10.2753/EUE1056-4934420104]

12] Chauhan A, Goel M, Arora RG. Motivation among Higher Education Academicians: A Factor Analytical Approach. ANVESHAK-Int J Manag 2018; 7(1): 172-89.

13] Nessipbayeva O, Dalayeva T. Developmental perspectives of higher education in the post-Soviet countries (for the cases of Kazakhstan, Uzbekistan, Kyrgyzstan, Tajikistan and Turkmenistan). Procedia Soc Behav Sci 2013; 10(89): 391-6.

[http://dx.doi.org/10.1016/j.sbspro.2013.08.865]

[14] Ardichvili A, Gasparishvili A. Socio-cultural values, internal work culture and leadership styles in four post-communist countries: Russia, Georgia, Kazakhstan and the Kyrgyz Republic. Int J Cross Cult Manag 2001; 1(2): 227-42.

[http://dx.doi.org/10.1177/147059580112006]

[15] Bendas TV. Russia and Kazakhstan: ethnocultural and gender differences. Orenburg State University Herald 2003; 1(7): 51-9.

[16] Bargh JD, Chartrand T. The mind in the middle: A practical guide to priming and automaticity research.Handbook of research methods in social and personality psychology. Cambridge, UK: Cambridge University Press 2000; pp. 253-85.

[17] Schein EH. Career anchors revisited: Implications for career development in the 21st century. Acad Manage Perspect 1996; 10(4): 80-8.

[http://dx.doi.org/10.5465/ame.1996.3145321]

[18] Potemkina OF. Methods of diagnosis of the socio-psychological attitudes of the individual in the motivational-need sphere. Moscow, Russia: Academia 2001

[19] Akizhanova DM, Satenova SK. Cultural values of Kazakh people and negotiations in Kazakkhstan. Perspectives of science and education 2013; 1(5): 15-9.

20] Esenova S. Soviet nationality, identity, and ethnicity in Central Asia: Historic narratives and Kazakh ethnic identity. J Muslim Minor Aff 2002; 22(1): 11-38.

[http://dx.doi.org/10.1080/13602000220124818]

[21] Calkins CM. Developing and Measuring Faculty Motivation to Teach in Higher Education (Doctoral dissertation, University of Nevada, Las Vegas) [Accessed on 21.12.2018];

[22] Aubakirova SS, Ismagambetova ZN, Karabayeva AG, et al. Tolerance Issue in Kazakh Culture. Int J Environ Sci Educ 2016; 11(12): 5034-48

[23] Fadeyeva IM. The motivation of university teachers as a factor in improving the quality of higher education. Mordovian University Herald 2007; 7(1): 12-5.

[24] Smolentseva A. Challenges to the Russian academic profession. High Educ 2003; 45(4): 391-424

[http://dx.doi.org/10.1023/A:1023954415569]

[25] Alexander U, Evgeniy P. The entrepreneurial university in Russia: From idea to reality. Procedia Soc Behav Sci 2012; 9(52): 45-51. [http://dx.doi.org/10.1016/j.sbspro.2012.09.440]

[26] Nurtazina RA. Integration of education of Kazakhstan. Integra Educ 2004; 1(2): 11-5.

[27] Efendiyev AG, Reshetnikova KV. Professional activities of university teachers of Russian universities: Problems and main trends. Educational issues 2008; 2(1): 10-5.

[28] Dyusekeyev KA, Shikulskaya O M. Analysis of the effectiveness of remuneration systems for university employees in Russia and Kazakhstan. Modern science: current problems and solutions 2014; 2(12): 76-8.

(c) 2019 Turgumbayeva et al.

This is an open access article distributed under the terms of the Creative Commons Attribution 4.0 International Public License (CC-BY 4.0), a copy of which is available at: https://creativecommons.org/licenses/by/4.0/legalcode. This license permits unrestricted use, distribution, and reproduction in any medium, provided the original author and source are credited. 